\title{
Accuracy of immediate antepartum ultrasound estimated fetal weight and its impact on mode of delivery and outcome - a cohort analysis
}

\author{
Johannes Stubert ${ }^{1 *}$ D, Adam Peschel ${ }^{2}$, Michael Bolz ${ }^{1}, \ddot{A} n n e$ Glass $^{3}$ and Bernd Gerber ${ }^{1}$
}

\begin{abstract}
Background: The aim of the study was to investigate the accuracy of ultrasound-derived estimated fetal weight (EFW) and to determine its impact on management and outcome of delivery.

Methods: In this single-center cohort analysis, women with a singleton term pregnancy in the beginning stages of labor were included. Women with immediately antepartum EFW $(N=492)$ were compared to women without ultrasound ( $N=515)$.

Results: EFW was correct (deviation from birth weight $\leq 10 \%)$ in $72.2 \%(355 / 492)$ of patients with fetal biometry; 19. $7 \%$ (97/492) were underestimated, and 8.1\% (40/492) were overestimated. Newborns with a lower birth weight were more frequently overestimated, and newborns with higher birth weight were more frequently underestimated. The mean difference between EFW and real birth weight was $-114.5 \mathrm{~g}$ (standard deviation $\pm 313 \mathrm{~g}, 95 \%$ confidence interval 87.1-142.0). The rate of non-reassuring fetal heart tracing $(9.8 \%$ vs. $1.9 \%, P<0.001)$ and of caesarean delivery (9.1\% vs. 5.0\%, $P=0.013$ ) was higher in women with EFW. Overestimation was associated with an increased risk for delivery by caesarean section (odds ratio 2.80; 95\% confidence interval 1.2-6.5, $P=0.017$ ). After adjustment, EFW remained associated with increased non-reassuring fetal heart tracing (odds ratio 4.73; $95 \%$ confidence interval 2.3-9.6) and caesarean delivery (odds ratio 1.86; 95\% confidence interval 1.1-3.1). The incidence of perineal tears of grade $3 / 4$, shoulder dystocia, postnatal depression and neonatal acidosis did not differ between groups.
\end{abstract}

Conclusions: Antepartum ultrasound-derived EFW does not improve maternal and fetal outcome and is therefore not recommended.

Keywords: Prenatal ultrasonography, Fetal biometry, Fetal weight estimation, Birth weight, Accuracy

\section{Background}

Usually, first presentation to the delivery room of pregnant women at term occurs with onset of regular contractions. Although ultrasound examination of the fetus during admission is not routinely recommended, it is a common practice in German hospitals. There may be various reasons for this approach. On the one hand it gives certain information about fetal position and

\footnotetext{
* Correspondence: johannes.stubert@uni-rostock.de

${ }^{1}$ Department of Obstetrics and Gynecology, University of Rostock, Suedring 81, 18059 Rostock, Germany

Full list of author information is available at the end of the article
}

placental location that may be of relevance for management of the delivery. Otherwise, especially residents can gain experience in performance of ultrasound. From own experience it can be stated that ultrasound-derived estimation of fetal weight (EFW) is nearly always part of such an examination. In that way, fetuses with suspicion of macrosomia will also be identified. Fetal macrosomia is a known risk factor for adverse obstetric outcome parameters, such as shoulder dystocia, failure of progression and third and fourth-degree perineal tears [1-3]. The performance of ultrasound-derived EFW at the beginning of birth is not part of the recommendations of

(C) The Author(s). 2018 Open Access This article is distributed under the terms of the Creative Commons Attribution 4.0 International License (http://creativecommons.org/licenses/by/4.0/), which permits unrestricted use, distribution, and 
the international guidelines. However, if fetal macrosomia is assumed, particularly $>4500 \mathrm{~g}$ and in combination with diabetes, a delivery by caesarean section should be considered to reduce the potential morbidity $[4,5]$. Although there is only weak evidence for this approach, the determination of EFW could be of forensic relevance in cases of birth-related damage; subsequently, claims are continuously increasing in Germany and other countries [6]. Consequently, knowledge of EFW could become legally relevant, and it could therefore influence the management of delivery and facilitate decisions in favor of a secondary caesarean section even if a vaginal delivery was initially intended. The aim of this study was to correlate the immediate antepartum ultrasound-derived EFW with the birth weight and to investigate if knowledge of EFW influences a) the management of delivery and b) maternal and fetal outcome parameters.

\section{Methods}

\section{Trial design and participants}

The study was performed at the Department of Obstetrics and Gynecology of the University of Rostock between May 2012 and February 2013. Written informed consent was obtained from all participants. A total of 1007 women with an uncomplicated singleton pregnancy and onset of regular contractions between $37+0$ and 41 +0 weeks of gestation were included. The exclusion criteria were premature onset of labor, multiple pregnancies, preterm membrane rupture, cervix dilatation > $5 \mathrm{~cm}$, planned primary caesarean delivery, non-vertex presentation and suspected intrauterine growth restriction. The trial meets the criteria of a quasi-randomized design. The condition of the cervix in all the women was classified by a modified Bishop-Score [7]. Mothers with a mature cervix (score $>12$ ) were directly prepared for delivery without ultrasound $(N=492)$; otherwise (score $\leq 12$ ), ultrasound with EFW was additionally performed $(N=515)$. All women progressed spontaneously to the active phase of the first stage of labor without pharmacological or mechanical techniques of cervical ripening. In all cases, delivery was within seven days after EFW.

\section{Outcome measures}

EFW was calculated using fetal abdomen circumference, the length of the femur and the biparietal diameter according to the formula of Hadlock II [8]. GE Logiq P6 (GE Medical Systems, Milwaukee, WI, USA) was used for sonographic examination. Residents had $>1$ year of experience in ultrasound examination, and specialists had $>5$ years of experience. Gestational age was calculated from the first day of the last menstrual period and was corrected by ultrasound if measurements of the crown-rump-length during the first trimester were different after more than 7 days. Intrapartum assessment was based on continuous fetal heart rate monitoring with a classification of heart rate patterns according to the FIGO-guidelines. The appraisal of cardiotocography and concomitant proceedings including fetal blood sampling, intrauterine resuscitation with $\beta$-mimetics or operative termination of pregnancy was decided by the specialist on duty. The following outcome parameters were registered: shoulder dystocia, third and fourthdegree perineal tears, neonatal depression (5'APGAR $\leq 7$ ) and neonatal acidosis (umbilical arterial blood $\mathrm{pH}<7.10$ or base excess $<-10 \mathrm{mmol})$. Shoulder dystocia was assumed if a delayed development of the fetal shoulders required medical care by obstetric procedures.

\section{Statistical analysis}

All data were stored and analyzed using the IBM SPSS statistical package 23.0 (SPSS Inc. Chicago, IL, USA) and Excel 2010 (Microsoft Corporation, Redmond, WA, USA). Descriptive statistics included mean and standard deviation (SD) for parametric as well as median and interquartile range (IQR) for non-parametric parameters. Frequency and relative percentage were used for categorical data. Testing for differences of continuous variables between groups was accomplished by the Student's t-test or Mann-Whitney U-test as appropriate. Comparison of categorical variables between the groups was performed using the chi-square test or the Fisher's exact test. $P$ values resulted from two-sided statistical tests, and values $<0.05$ were considered statistically significant. For the outcome parameters, caesarean section and nonreassuring fetal heart tracing odds ratios (ORs) were computed. Here, the logistic regression model was used to assess the independence of specific outcome parameters. In the multivariate model, the ORs were adjusted to maternal body mass index, nulliparity, gestational age at delivery, maternal weight gain during pregnancy, gestational diabetes, maternal age and birth weight. Correlations were computed using the Pearson's correlation coefficient. The 95\% confidence interval (CI) was reported to demonstrate the reliability of the estimated parameters. The percentage difference between EFW and real birth weight was calculated by the following formula: relative difference $\%=[(E F W$ - birth weight $) /$ birth weight] $\times 100$. A relative difference $\pm 10 \%$ was regarded as correct.

Receiver operating characteristic (ROC) curves were calculated for identification of hypertrophic and hypotrophic newborns by EFW and the areas under the curves (AUCs) were reported. The cut-off values were calculated for false positive rates of $5 \%$ and $10 \%$ and corresponding detection rate (DR) is given. 


\section{Results}

\section{Patients' characteristics}

The baseline characteristics of the included women were generally well balanced between both groups with only little differences (Table 1). The proportion of nulliparous women was slightly, but significant higher in the EFW group (58.5\% vs. $52.2 \%$; $P=0.049$ ). Women who obtained EFW had also a higher mean weight gain during pregnancy (mean difference $0.79 \mathrm{~kg}, P=0.049$ ). Although mean gestational age at delivery was higher in women with EFW $(P=0.006)$, the mean difference was only two days. Inhomogeneity was also observed for the frequency of hypertensive disorders with more cases in women with EFW. Only one patient with hypertension got a caesarean section after EFW.

\section{Accuracy of fetal weight estimation}

Antepartum assumed EFW and real birth weight were well correlated with a Pearson's correlation coefficient of $r=0.778$ and a coefficient of determination of $\mathrm{R}^{2}=0.606$ (Fig. 1). In the entire group, mean birth weight was underestimated by $-113.6 \mathrm{~g} \pm 313 \mathrm{~g}$ (95\% CI -141.3 to $85.9 ; P<0.001)$, which correlates to a mean relative difference of $-2.75 \% \pm 8.8 \%$ (95\% CI -3.5 to $-2.0 ; P<0$. 001). The absolute estimation error (sum of all difference values/n) was $261.5 \mathrm{~g}$. Of all EFW, $72.2 \%$ were evaluated exactly with an underestimation of $19.7 \%$ and an overestimation of $8.1 \%$. The accuracy depended on birth weight with an increase in overestimation at a birth weight $<3000 \mathrm{~g}$ and an increase in underestimation at a birth weight $\geq 4000 \mathrm{~g}$ (Fig. 2). Best performance was achieved in the subgroup of newborns with a birth weight between 3000 and $3900 \mathrm{~g}$ and ultrasound performed by specialists $(n=151)$ : mean difference $-86.6 \mathrm{~g} \pm 275 \mathrm{~g}$ (95\% CI -130.8 to $-42.5, P<0.001$ ) and mean relative difference $-2.30 \% \pm 7.9 \%$ (95\% CI -3.6 to $-1.0, P<0.001)$. The accuracy was $79.5 \%$ in this subgroup $(74.0 \%$ for residents, $76.6 \%$ all investigators, $P=0.251$ ). The accuracy between residents and specialists was also not different in the total study population $(69.1 \%$ vs. $75.6 \%, P=0.129)$. However, in the subgroup of newborns with a birth weight $>4000 \mathrm{~g}$, the specialists conducted significantly more correct measurements compared to the residents (73.0\% vs. $45.2 \%, P=0.022$ ). Relative differences between EFW and neonatal birth weight were neither correlated to pregravid maternal body mass index, maternal weight gain during pregnancy, parity nor to gestational age at delivery (all $P>0.05$ ).

\section{Test characteristics for detection of hyper- and hypotrophic newborns}

DRs for hypertrophia (birth weight $\geq 4500$ g) were 83 . $3 \%, 58.3 \%$ and $41.7 \%$ at an EFW cut-off-level of $\geq 4000 \mathrm{~g}$, $4300 \mathrm{~g}$ and $4500 \mathrm{~g}$ with the corresponding FPRs of $7.9 \%$, $1.4 \%$ and $0.4 \%$. ROC-analysis resulted in an AUC of 0.92 (95\% CI 0.81 to $1.00, P<0.001)$. Calculated DRs were $83 \%$ at a FPR of $10 \%$ (EFW cut-off $3900 \mathrm{~g}$ ) and $67 \%$ at a FPR of 5\% (EFW cut-off $4100 \mathrm{~g}$ ).

Table 1 Patient and fetal characteristics of study participants

\begin{tabular}{|c|c|c|c|}
\hline Characteristic & Patients with EFW $(N=492)$ & Patients without EFW $(N=515)$ & $p$ \\
\hline Age, y & $28.7 \pm 5.2$ & $28.7 \pm 5.1$ & $0.866^{\mathrm{a}}$ \\
\hline Gravidity, n & $2(1-3)$ & $2(1-3)$ & $0.478^{b}$ \\
\hline Parity, n & $1(1-2)$ & $1(1-2)$ & $0.049^{b}$ \\
\hline Body mass index (pregravid), $\mathrm{kg} / \mathrm{m}^{2}$ & $23.8 \pm 4.8$ & $23.6 \pm 5.2$ & $0.623^{\mathrm{a}}$ \\
\hline Maternal weight gain in pregnancy, kg & $15.92 \pm 5.9$ & $15.14 \pm 6.1$ & $0.049^{\mathrm{a}}$ \\
\hline Gestational diabetes, $\mathrm{n}$ & $32(6.5 \%)$ & $22(4.3 \%)$ & $0.116^{c}$ \\
\hline Hypertensive diseases, $\mathrm{n}$ & $13(2.6 \%)$ & $3(0.6 \%)$ & $0.009^{c}$ \\
\hline Duration of the second stage, $\min$ & $46.4 \pm 50.0$ & $46.0 \pm 47.5$ & $0.902^{\mathrm{a}}$ \\
\hline Gestational age at delivery, $\mathrm{d}$ & $280.2 \pm 8.7$ & $278.8 \pm 7.8$ & $0.006^{\mathrm{a}}$ \\
\hline Birth weight, $g$ & $3528 \pm 485$ & $3540 \pm 496$ & $0.718^{\mathrm{a}}$ \\
\hline Birth weight $\geq 4500 \mathrm{~g}, \mathrm{n}$ & $12(2.4 \%)$ & $16(3.1 \%)$ & $0.519^{c}$ \\
\hline Birth length, $\mathrm{cm}$ & $50.4 \pm 2.2$ & $50.4 \pm 2.1$ & $0.795^{\mathrm{a}}$ \\
\hline Head circumference, $\mathrm{cm}$ & $35.1 \pm 1.4$ & $35.0 \pm 1.4$ & $0.386^{\mathrm{a}}$ \\
\hline Head circumference $\geq 38 \mathrm{~cm}, \mathrm{n}$ & $20(4.1 \%)$ & $13(2.5 \%)$ & $0.160^{c}$ \\
\hline Umbilical arterial blood pH & $7.27 \pm 0.07$ & $7.28 \pm 0.07$ & $0.378^{\mathrm{a}}$ \\
\hline Base excess, mmol/L & $-4.64 \pm 2.89$ & $-4.39 \pm 2.84$ & $0.167^{\mathrm{a}}$ \\
\hline 5'-APGAR-Score & $10(9-10)$ & $10(9-10)$ & $0.695^{b}$ \\
\hline
\end{tabular}

a Student's t-test for independent samples

${ }^{b}$ Mann-Whitney U-test by ranks ${ }^{c}$ Pearson's X2-test for homogeneity 


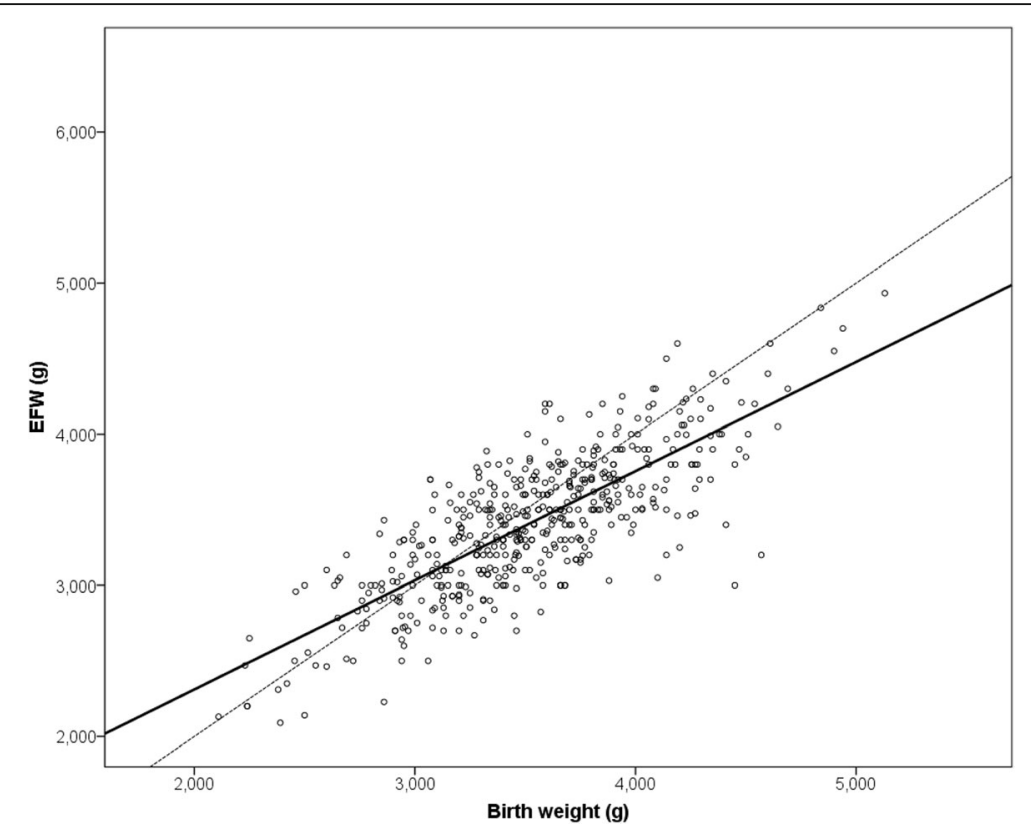

Fig. 1 Scatter plot of neonatal birth weight and antepartum ultrasound-derived estimated fetal weight: The solid line represents the calculated linear regression with $y=0.722^{*} x+866$ and a coefficient of determination $R^{2}=0.606$. The dotted line represents the ideal regression with $y=x$. Newborns with lower birth weight were overestimated, and newborns with higher birth weight were underestimated by antepartum ultrasound

DRs for hypotrophia (birth weight $\leq 2500 \mathrm{~g}$ ) were 60 . $9 \%$ and $47.8 \%$ at an EFW cut-off-level of $\leq 2700 \mathrm{~g}$ and $2500 \mathrm{~g}$ with the corresponding FPRs of $2.8 \%$ and $0.9 \%$. The AUC was 0.97 (95\% CI 0.94-1.00, $P<0.001)$. Calculated DRs were both $83 \%$ at a FPR of $5 \%$ (EFW cut-off $2760 \mathrm{~g}$ ) and at a FPR of $10 \%$ (EFW cut-off $2900 \mathrm{~g}$ ).

\section{Mode of delivery and outcome parameters between groups}

As shown in Table 2, women with antepartum EFW underwent caesarean section more frequently $(9.1 \%$ vs. $5.0 \%, P=0.013)$ with an adjusted OR of 1.86 (95\% CI 1.1 to 3.1; Table 3). Among patients with caesarean delivery,

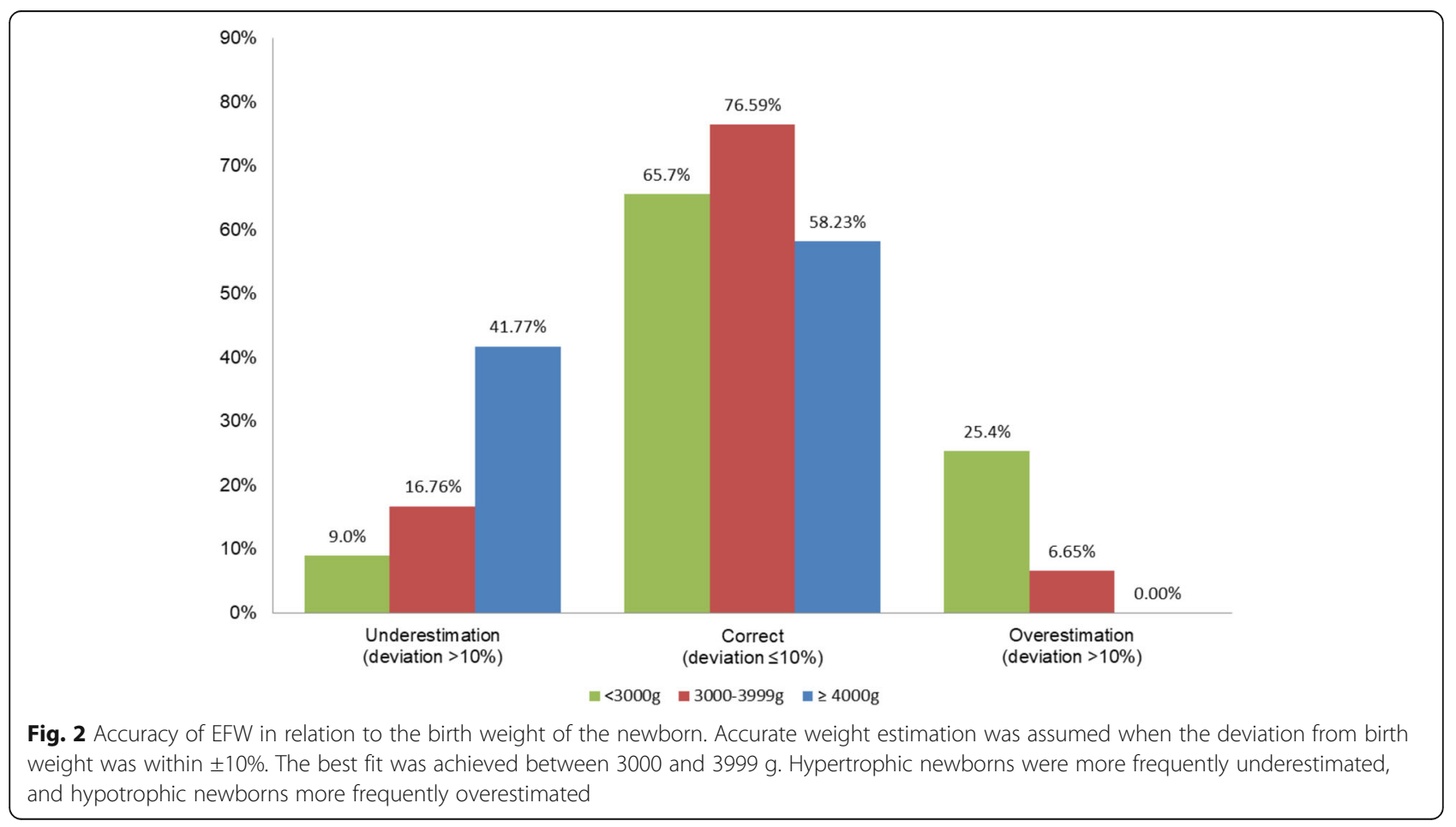


Table 2 Mode of delivery, maternal and short-term fetal outcome parameters

\begin{tabular}{llll}
\hline Characteristic & Patients with EFW $(N=492)$ & Patients without EFW $(N=515)$ & $P^{*}$ \\
\hline Caesarean delivery, $\mathrm{n}$ & $45(9.1 \%)$ & $26(5.0 \%)$ & 0.013 \\
Failure to progress, $\mathrm{n}$ & $28(5.7 \%)$ & $17(3.3 \%)$ & 0.069 \\
Nonreassuring fetal assessment & $48(9.8 \%)$ & $10(1.9 \%)$ & $<0.001$ \\
Shoulder dystocia & $2(0.4 \%)$ & $2(0.4 \%)$ & 1.000 \\
Perineal tear III//V & $1(0.2 \%)$ & $2(0.4 \%)$ & $13(2.5 \%)$ \\
5'APGAR $\leq 7^{\prime}$ & $12(2.4 \%)$ & $3(0.6 \%)$ & 1.000 \\
Umbilical arterial blood pH $<7.10$ & $6(1.2 \%)$ & $7(1.4 \%)$ & 0.330 \\
Base excess $<-10 \mathrm{mmol} / \mathrm{L}$ & $10(2.0 \%)$ & & 0.467 \\
\hline
\end{tabular}

${ }^{*}$ Fisher's exact test

we did not observe a difference in birth weight (3504 \pm $667.9 \mathrm{~g}$ without and $3474 \pm 671.9 \mathrm{~g}$ with EFW, $P=0$. 858). There were also no differences with respect to mean head circumference and maternal weight gain during pregnancy (data not shown). EFW did not differ between patients with and without caesarean delivery $(P=$ 0.262).

However, the accuracy of EFW was different between both groups. In patients who underwent a caesarean section, the EFW was significantly more frequently overestimated $(17.8 \%$ vs. $7.2 \%, P=0.013)$ with an OR of 2.80 (95\% CI 1.2-6.5, $P=0.017$ ). The rate of caesarean section did not differ significantly between classes of birth weight, but there was a trend in higher numbers of hypo- and hypertrophic newborns $(16.4 \%<3000 \mathrm{~g}, 7.5 \%$ 3000-3999 g and $10.1 \% \geq 4000 \mathrm{~g} ; P=0.065)$.

Interestingly, non-reassuring fetal heart tracing was more common in women with EFW in the entire study group (9.8\% vs. $1.9 \%, P<0.001$; adjusted $\mathrm{OR}=4.73$, $95 \%$ CI $2.3-9.6, P<0.001)$ and also if only patients who underwent caesarean delivery were considered (31.1\% vs. $7.7 \%, P=0.037$ ). Frequency of non-reassuring fetal heart tracing did not differ between patients with and without overestimation of EFW (8.3\% vs. 8.1\%, $P=0.957)$.

Patients with known EFW revealed a trend to a higher frequency of failure to progress $(5.7 \%$ vs. $3.3 \%, P=0$. 069). A similar trend was observed if only patients with overestimation of EFW were considered (17.9\% vs. $7.5 \%$, $P=0.067$; OR $=2.67$ (95\% CI 0.9-7.4, $P=0.061$ ), but differences were restricted to nulliparous women (Table 3).

Although knowledge of EFW increased the rate of caesarean section, the short term fetal and maternal morbidity was not improved in this group (Table 2). The results were also not significant even if we compared a composite morbidity endpoint including all single outcome parameters ( $13.3 \%$ vs. $30.8 \%, P=0.075)$.

\section{Discussion}

In accordance with numerous other studies, our results confirmed that the ultrasound-derived EFW during labor at term is an appropriate diagnostic tool, with an average accuracy of $70 \%$ within a relative difference of $\pm 10 \%$ to the real birth weight [9-13]. We also observed a systematic underestimation of fetal weight in the total population. The frequency of underestimation was highest in newborns with a birth weight $>4000 \mathrm{~g}$. In this subgroup, only $58 \%$ were correctly estimated, and none were overestimated. Therefore, EFW at term is of limited value for identification of fetal macrosomia. In our study, the accuracy did not depend on the pregravid maternal body mass index. However, there were only five women with a body mass index $\geq 40$ in our study cohort. Other studies demonstrated a decrease of accuracy when the body mass index increased [14-17]. Although accuracy was nearly the same between residents and specialists in the total study population, specialists had more correct results when only newborns with a birth weight $>4000 \mathrm{~g}$ were considered.

In a postpartum study Kehl et al. directly measured the two-dimensional biometric parameters head circumference, abdominal circumference and thigh length (instead of the ultrasound parameter femur length) on 419 term newborns and computed the best-fitting formula for calculation of birth weight by a forward regression analysis [18]. Results were validated on validation group of further 209 newborns. With their new formulae a further increase of accuracy with avoidance of a systematic error was possible. They concluded that a good sonographic weight formula should have an accuracy of $80 \%$ within a discrepancy level of $10 \%$ with a SD of about $7 \%$ and without a systematic error. However the new formulae also revealed the problem of a general overestimation of birth weight in the lower weight range and an underestimation at the upper end of the range. Furthermore, as the authors circumvented the performance of ultrasound they did not consider the influence of measurement errors resulting from oligohydramnios, thick abdominal wall, deep pelvic head position and inaccuracy in measurement of the abdominal circumference. In a recent study Eggebø et al. demonstrated that it is possible to achieve the quality of fetal weight estimation postulated by Kehl and colleagues [19]. In this study the 
Table 3 Association between estimation of fetal weight and risk of caesarean delivery, nonreassuring fetal assessment and failure to progress. ORs were adjusted to maternal body mass index, nulliparity, gestational age at delivery, maternal weight gain during pregnancy, gestational diabetes, maternal age and birth weight

\begin{tabular}{clllll}
\hline & Patients without EFW & Patients with EFW & P $^{*}$ & crude OR (95\%Cl) & adjusted OR (95\%Cl) \\
\hline Caesarean delivery, $\mathrm{n}$ & $26 / 515(5.0 \%)$ & $45 / 492(9.1 \%)$ & 0.013 & $2.80(1.2-6.5)$ & $1.86(1.1-3.1)$ \\
Nulliparous women & $18 / 269(6.7 \%)$ & $27 / 288(9.4 \%)$ & 0.278 & $1.44(0.8-2.7)$ & $1.41(0.7-2.7)$ \\
Multiparous women & $8 / 246(3.3 \%)$ & $18 / 204(8.8 \%)$ & 0.014 & $2.88(1.2-6.8)$ & $3.11(1.3-7.8)$ \\
Nonreassuring fetal assessment, $\mathrm{n}$ & $10 / 515(1.9 \%)$ & $48 / 492(9.8 \%)$ & $<0.001$ & $5.46(2.7-10.9)$ & $4.73(2.3-9.6)$ \\
Nulliparous women & $6 / 269(2.2 \%)$ & $36 / 288(12.5 \%)$ & $<0.001$ & $6.26(2.6-15.1)$ & $5.37(2.2-13.2)$ \\
Multiparous women & $4 / 246(1.6 \%)$ & $12 / 204(5.9)$ & 0.020 & $3.78(1.2-11.9)$ & $3.57(1.1-11.6)$ \\
Failure to progress, $n$ & $17 / 515(3.3 \%)$ & $28 / 492(5.7 \%)$ & 0.069 & $1.77(1.0-3.3)$ & $1.59(0.8-3.0)$ \\
Nulliparous women & $12 / 269(4.5 \%)$ & $27 / 288(9.4 \%)$ & 0.030 & $2.21(1.1-4.5)$ & $2.00(1.0-4.1)$ \\
Multiparous women & $5 / 246(2.0 \%)$ & $1 / 204(0.5 \%)$ & 0.228 & $0.24(0.0-2.5)$ & $0.33(0.0-3.2)$ \\
\hline
\end{tabular}

"Fisher's exact test

ultrasound examination was performed on 419 women on day 290 of pregnancy. With an algorithm including gestational age the authors reported of an accuracy of $83 \%$ within $10 \%$ discrepancy, a SD of $7.6 \%$ and without a systematic error (mean difference between birth weight and FWF was $-6 \mathrm{~g}$ ). Even if these results were impressive, the detection rates for macrosomia and small for gestational age fetuses were only $54 \%$ and $49 \%$ on false positive rate of $5 \%$. In comparison, sensitivity was not superior to our results (using the less accurate formula of Hadlock II) for detection of the cases of most clinical importance.

Consequently, EFW at term is not reliable for prediction of macrosomia and is therefore not recommended by several guidelines. Taking the international guidelines into account, the rate of caesarean delivery should not be higher if fetal weight was estimated immediately before delivery. However, in the present study, it was nearly doubled. The increase was independent of fetal weight, and it was not restricted to macrosomic fetuses. However, the overestimation of fetal weight was associated with an increased risk for caesarean delivery. In a retrospective cohort analysis, EFW was also associated with an increased risk for caesarean delivery (OR 1.44, 95\% CI 1.1-1.9) [20]. Similar results were found in a recently published big cohort study of 64,030 women at term who attempted vaginal delivery [21]. In this study the knowledge of EFW was significantly associated with an increased risk of caesarean delivery (adjusted OR 1.44 (95\% CI 1.31-1.58, $P<0.001)$. In contrast to our results, several studies correlated the risk of caesarean delivery with an increase of the EFW > $3500 \mathrm{~g}$ [20-22]. Our data supported the study results of Blackwell et al., which showed that overestimation of fetal weight (in contrast to absolute weight estimation) was an independent risk factor for caesarean delivery (OR 4.8, 95\% CI 1.5-15.2) [23]. In a further retrospective cohort analysis, the overestimation of large gestational age fetuses was identified as a risk factor for caesarean delivery in newborns with birth weight between 2500 and 3499 g (OR 2.82, 95\% CI $1.62-4.84, P<0.01)$ as well as $3500-4500 \mathrm{~g}$ (OR 3.47, 95\% CI 2.06-5.88, $P<0.01$ ) [24]. So there is rising evidence, that knowledge of EFW by itself is a risk factor for decision to a caesarean delivery.

In our study, the increase of the caesarean delivery rate was neither accompanied by a decrease of fetal nor maternal morbidity. In particular, no differences in shoulder dystocia and third and fourth degree perineal tears were observed. In a case-control study of 1938 women with antenatal EFW eight cases of shoulder dystocia were observed [22]. In four cases dystocia occurred in women with EFW < 4000 g. Although fetal macrosomia is a known risk factor for the development of shoulder dystocia, 20-65\% of all cases of shoulder dystocia occur in children with a birth weight below $4000 \mathrm{~g}$ [25]. In a recent study by Peleg et al. on newborns with birth weight $>4000 \mathrm{~g}$ (238 non-diabetic low risk women with EFW $\geq 4000 \mathrm{~g}$ and 205 women with EFW $<4000 \mathrm{~g}$ ), the risk of caesarean delivery was 9.0-times higher when macrosomia was correctly assumed, but there was no difference in the rate of shoulder dystocia [26]. Overall, there is strong evidence that EFW increases the rate of caesarean delivery with no impact on the rate of shoulder dystocia [27-32].

In the EFW group, a non-reassuring fetal heart tracing was diagnosed more often, although we found no differences in short-term fetal outcome. This is a new observation that is difficult to explain. We hypothesize that the obstetricians were hypercritical when interpreting the fetal heart rate patterns, and they were seeking an indication to perform caesarean delivery following the overestimation of fetal weight.

The strengths of this study are its prospective, quasirandomized design, which maintained mostly well balanced patient characteristics between both groups. The availability of outcome parameters allowed statements 
regarding not only the accuracy of EFW and its influence on the mode of delivery but also regarding the fetal and maternal morbidity.

A potential bias in our results may be founded by the different maturity of the cervix at inclusion. Several studies observed a correlation between cervical dilatation at admission and the risk of a caesarean section [33-37]. These studies compared patients with cervical dilatation of $0-3 \mathrm{~cm}$ to patients with dilatation of 4 to $10 \mathrm{~cm}$. Earlier admission to delivery room was associated with an increased risk of a caesarean delivery. However, essential differences to our study are obvious. First, we included only patients during the latent phase of labor with cervical dilatation $<5 \mathrm{~cm}$ [38]. Second, as even postulated in some of these studies, the observed increase of caesarean delivery was probably caused by physician intervention, e.g. augmentation of labor with oxytocin $[34,35,37]$. In contrast, in our study intervention for cervical ripening or labor augmentation was avoided during the latent phase of labor. At least, our observed differences between patients with and without EFW were confirmed by the increased risks for caesarean section in patients with overestimation of EFW. In this inner group comparison a bias related to criterions of inclusion can be clearly excluded.

However, it cannot be ruled out, that the differences of cervical maturity between our groups may have an influence on the frequency of caesarean section. Further limitations of our study are the limited patient numbers and the generally low number of outcome events. Hence, we presented a composite outcome. There were some additional imbalances between the groups in terms of parity, maternal weight gain during pregnancy, gestational age at delivery and the frequency of hypertensive disorders (which were generally low); therefore, we computed a logistic regression analysis by adjusting for these possible confounding variables.

\section{Conclusion}

Antepartum ultrasound derived EFW is, although widely used, of limited clinical benefit. Its accuracy substantially decreases in the detection of hypo- and hypertrophic fetuses. The overestimation of fetal weight correlates with an increased risk of caesarean delivery. Nevertheless, antepartum ultrasound-derived EFW does not improve maternal and fetal outcome and is therefore not recommended.

\footnotetext{
Abbreviations

AUC: area under the curve; Cl: confidence interval; DR: detection rate; EFW: estimated fetal weight; FPR: false positive rate; IQR: interquartile range; OR: odds ratio; ROC: receiver operating characteristic; SD: standard deviation
}

\section{Availability of data and materials}

The datasets during and/or analysed during the current study available from the corresponding author on reasonable request.

\section{Authors' contributions}

JS analyzed and interpreted the patient data and was a major contributor in drafting the manuscript. AP collected the raw data and also analyzed and interpreted them. MB made substantial contribution to conception and design of the study. ÄG was responsible for analysis and interpretation of data as well as conception and design of the study. BG interpreted data and was a major contributor in drafting the manuscript. All authors have been involved in revising the manuscript critically for important intellectual content and gave final approval of the version to be published.

\section{Ethics approval and consent to participate}

The study protocol was approved by the IRB (ethics committee of the University of Rostock): Reg.-No.: A 2017-0148. Written informed consent was obtained from all participants.

\section{Competing interests}

JS reported of no conflict of interest. AP reported of no conflict of interest. MB reported of no conflict of interest. ÄG reported of no conflict of interest. $B G$ reported of no conflict of interest.

\section{Publisher's Note}

Springer Nature remains neutral with regard to jurisdictional claims in published maps and institutional affiliations.

\section{Author details}

Department of Obstetrics and Gynecology, University of Rostock, Suedring 81, 18059 Rostock, Germany. ${ }^{2}$ Department of Radiology, Hospital Asklepios Klinik Barmbek, Hamburg, Germany. ${ }^{3}$ Institute for Biostatistics and Informatics in Medicine, University of Rostock, Rostock, Germany.

Received: 8 February 2017 Accepted: 24 April 2018

Published online: 02 May 2018

\section{References}

1. Meister MR, Cahill AG, Conner SN, Woolfolk CL, Lowder JL: Predicting Obstetric Anal Sphincter Injuries in a modern obstetric population. Am J Obstet Gynecol. 2016;215(3):310.e1-7.

2. Hill MG, Cohen WR. Shoulder dystocia: prediction and management. Women's Health. 2016;12(2):251-61.

3. Executive summary: Neonatal brachial plexus palsy. Report of the American College of Obstetricians and Gynecologists' task force on neonatal brachial plexus palsy. Obstet Gynecol. 2014;123(4):902-4.

4. Shoulder Dystocia [https:/www.rcog.org.uk/globalassets/documents/ guidelines/gtg_42.pdf]. Accessed 28 Apr 2018.

5. Sokol RJ, Blackwell SC, American College of O, Gynecologists. Committee on Practice B-G. ACOG practice bulletin: shoulder dystocia. Number 40, November 2002. (replaces practice pattern number 7, October 1997). Int J Gynaecol Obstet. 2003;80(1):87-92.

6. Uphoff R, Hindemith J. The civil liability of obstetricians. Z Geburtshilfe Neonatol. 2011;215(6):223-9.

7. Jung H, Lamberti G, Wilms G. Die Geburtsprognose bei der Einleitung mittels eines modifizierten Geburtsreife-Score. Perinat Med. 1981;9: 306-9.

8. Hadlock FP, Harrist RB, Sharman RS, Deter RL, Park SK. Estimation of fetal weight with the use of head, body, and femur measurements-a prospective study. Am J Obstet Gynecol. 1985;151(3):333-7.

9. Farrell $T$, Holmes R, Stone P. The effect of body mass index on three methods of fetal weight estimation. BJOG. 2002;109(6):651-7.

10. Faschingbauer F, Dammer U, Raabe E, Schneider M, Faschingbauer C, Schmid M, Schild RL, Beckmann MW, Kehl S, Mayr A. Intrapartum sonographic weight estimation. Arch Gynecol Obstet. 2015;292(4):805-11.

11. Noumi G, Collado-Khoury F, Bombard A, Julliard K, Weiner Z. Clinical and sonographic estimation of fetal weight performed during labor by residents. Am J Obstet Gynecol. 2005;192(5):1407-9.

12. Peregrine $E, O$ 'Brien $P$, Jauniaux E. Clinical and ultrasound estimation of birth weight prior to induction of labor at term. Ultrasound Obstet Gynecol. 2007:29(3):304-9.

13. Sherman DJ, Arieli S, Tovbin J, Siegel G, Caspi E, Bukovsky I. A comparison of clinical and ultrasonic estimation of fetal weight. Obstet Gynecol. 1998; 91(2):212-7. 
14. Paganelli S, Soncini E, Comitini G, Palomba S, La Sala GB. Sonographic fetal weight estimation in normal and overweight/obese healthy term pregnant women by gestation-adjusted projection (GAP) method. Arch Gynecol Obstet. 2015:293(4):775-81.

15. Cody F, Unterscheider J, Daly S, Geary MP, Kennelly MM, McAuliffe FM, O'Donoghue K, Hunter A, Morrison JJ, Burke G, et al. The effect of maternal obesity on sonographic fetal weight estimation and perinatal outcome in pregnancies complicated by fetal growth restriction. J Clin Ultrasound. 2016; 44(1):34-9.

16. Kritzer S, Magner K, Warshak CR. Increasing maternal body mass index and the accuracy of sonographic estimation of fetal weight near delivery. $J$ Ultrasound Med. 2014;33(12):2173-9.

17. Aksoy H, Aksoy U, Karadag OI, Yucel B, Aydin T, Babayigit MA. Influence of maternal body mass index on sonographic fetal weight estimation prior to scheduled delivery. J Obstet Gynaecol Res. 2015;41(10):1556-61.

18. Kehl S, Schmidt U, Spaich S, Schild RL, Sutterlin M, Siemer J. What are the limits of accuracy in fetal weight estimation with conventional biometry in two-dimensional ultrasound? A novel postpartum study. Ultrasound Obstet Gynecol. 2012:39(5):543-8.

19. Eggebo TM, Klefstad OA, Okland I, Lindtjorn E, Eik-Nes SH, Gjessing HK. Estimation of fetal weight in pregnancies past term. Acta Obstet Gynecol Scand. 2017;96(2):183-9.

20. Little SE, Edlow AG, Thomas AM, Smith NA. Estimated fetal weight by ultrasound: a modifiable risk factor for cesarean delivery? Am J Obstet Gynecol. 2012;207(4):309.e301-6.

21. Froehlich RJ, Sandoval G, Bailit JL, Grobman WA, Reddy UM, Wapner RJ, Varner MW, Thorp JM Jr, Prasad M, Tita AT, et al. Association of Recorded Estimated Fetal Weight and Cesarean Delivery in attempted vaginal delivery at term. Obstet Gynecol. 2016;128(3):487-94.

22. Melamed N, Yogev Y, Meizner I, Mashiach R, Ben-Haroush A. Sonographic prediction of fetal macrosomia: the consequences of false diagnosis. $J$ Ultrasound Med. 2010;29(2):225-30.

23. Blackwell SC, Refuerzo J, Chadha R, Carreno CA. Overestimation of fetal weight by ultrasound: does it influence the likelihood of cesarean delivery for labor arrest? Am J Obstet Gynecol. 2009;200(3):340.e341-3.

24. Scifres $C M$, Feghali $M$, Dumont $T$, Althouse AD, Speer $P$, Caritis SN, Catov JM. Large-for-gestational-age ultrasound diagnosis and risk for cesarean delivery in women with gestational diabetes mellitus. Obstet Gynecol. 2015; 126(5):978-86.

25. Hansen A, Chauhan SP. Shoulder dystocia: definitions and incidence. Semin Perinatol. 2014;38(4):184-8.

26. Peleg D, Warsof S, Wolf MF, Perlitz $Y$, Shachar IB. Counseling for fetal macrosomia: an estimated fetal weight of $4,000 \mathrm{~g}$ is excessively low. Am J Perinatol. 2015;32(1):71-4.

27. Politi S, D'Emidio L, Cignini P, Giorlandino M, Giorlandino C. Shoulder dystocia: an evidence-based approach. J Prenat Med. 2010;4(3):35-42.

28. Gurewitsch ED. Optimizing shoulder dystocia management to prevent birth injury. Clin Obstet Gynecol. 2007;50(3):592-606

29. Mehta SH, Blackwell SC, Hendler I, Bujold E, Sorokin Y, Ager J, Kraemer T, Sokol RJ. Accuracy of estimated fetal weight in shoulder dystocia and neonatal birth injury. Am J Obstet Gynecol. 2005;192(6):1877-80. discussion 1880-1871

30. Parantainen J, Palomaki O, Talola N, Uotila J. Clinical and sonographic risk factors and complications of shoulder dystocia - a case-control study with parity and gestational age matched controls. Eur J Obstet Gynecol Reprod Biol. 2014:177:110-4.

31. Gherman RB, Chauhan S, Ouzounian JG, Lerner H, Gonik B, Goodwin TM. Shoulder dystocia: the unpreventable obstetric emergency with empiric management guidelines. Am J Obstet Gynecol. 2006;195(3):657-72.

32. Rouse DJ, Owen J. Prophylactic cesarean delivery for fetal macrosomia diagnosed by means of ultrasonography-a Faustian bargain? Am J Obstet Gynecol. 1999;181(2):332-8

33. Dias MA, Domingues RM, Schilithz AO. Nakamura-Pereira M, do Carmo Leal $\mathrm{M}$ : factors associated with cesarean delivery during labor in primiparous women assisted in the Brazilian public health system: data from a national survey. Reprod Health. 2016;13(Suppl 3):114.

34. Mikolajczyk RT, Zhang J, Grewal J, Chan LC, Petersen A, Gross MM. Early versus late admission to labor affects labor progression and risk of cesarean section in nulliparous women. Front Med. 2016:3:26.

35. Holmes P, Oppenheimer LW, Wen SW. The relationship between cervical dilatation at initial presentation in labour and subsequent intervention. BJOG. 2001;108(11):1120-4.
36. Rahnama P, Ziaei S, Faghihzadeh S. Impact of early admission in labor on method of delivery. Int J Gynaecol Obstet. 2006;92(3):217-20.

37. Bailit JL, Dierker L, Blanchard MH, Mercer BM. Outcomes of women presenting in active versus latent phase of spontaneous labor. Obstet Gynecol. 2005;105(1):77-9.

38. Zhang J, Troendle J, Mikolajczyk R, Sundaram R, Beaver J, Fraser W. The natural history of the normal first stage of labor. Obstet Gynecol. 2010; 115(4):705-10

\section{Ready to submit your research? Choose BMC and benefit from:}

- fast, convenient online submission

- thorough peer review by experienced researchers in your field

- rapid publication on acceptance

- support for research data, including large and complex data types

- gold Open Access which fosters wider collaboration and increased citations

- maximum visibility for your research: over $100 \mathrm{M}$ website views per year

At BMC, research is always in progress.

Learn more biomedcentral.com/submissions 